\title{
Is the clinical pattern of pediatric celiac disease changing? A thirty-years real-life experience of an Italian center
}

\author{
Melissa Pedretti ${ }^{1}$, Francesca Sbravati ${ }^{2}$, Davide Allegri ${ }^{3}$, Flavio Labriola ${ }^{2}$, Virginia Lombardo ${ }^{1}$, Enzo Spisni ${ }^{4}$, \\ Chiara Zarbo ${ }^{2}$ and Patrizia Alvisi ${ }^{2^{*}}$ (D)
}

\begin{abstract}
Objectives: Clinical presentation of pediatric celiac disease (CD) is heterogeneous and ever-evolving. Our aim is to highlight its changes throughout the years.

Methods: Data about clinical presentation of CD in children diagnosed between 1990 and 2020 at the CD Center of Maggiore Hospital, Bologna, were collected. Patients were stratified into groups based on the date [P1 (19902011), P2 (2012-2020)] and age [G1 (<2 years), G2 (2-5), G3 (6-11), G4 (12-18)] at diagnosis, then investigated by comparing CD clinical presentation in different periods and ages.

Results: 1081 children were selected. Mean age at diagnosis increases from 5.9 to 6.6 years from P1 to P2. Gastrointestinal Symptoms (GIs) are predominant, with a decline of diarrhea (47\%VS30\%) and an increase of constipation (4\%VS19\%) $(p<0.001)$. Among Extraintestinal symptoms (Els) a decrease of anemia (76\%VS43\%, $p=$ $0,001)$ is observed. Failure to Thrive (FTT) is stable throughout the years $(p=0.03)$, while screenings show a trend of increment (19\%VS23\%). Gls' frequency decline from G1 to G4 $(p=0,001)$, with reduction of diarrhea $(p<0.001)$, and rise of recurrent abdominal pain $(p=0,02)$. Els are more frequent at older ages, FTT in younger patients.

Conclusions: Changes in clinical presentation of CD have occurred in the last 30 years. We observe a reduction of severe and classic gastroenterologic symptoms and a rise of atypical ones, together with a growth of serological screenings and higher age at diagnosis. Awareness about CD clinical trends is crucial for a proper approach and early diagnosis.
\end{abstract}

Keywords: Pediatric celiac disease, Clinical pattern, Age at diagnosis, Clinical trend over time

\section{Introduction}

Celiac disease $(C D)$ is an immune-mediated glutendependent enteropathy in genetically predisposed individuals, with an estimated prevalence of $1 \%[1,2]$. The only effective treatment is lifelong strict Gluten-FreeDiet (GFD) [1]. However, this condition is often underdiagnosed because of heterogeneity of signs and

\footnotetext{
* Correspondence: patrizia.alvisi@ausl.bologna.it

${ }^{2}$ Pediatric Gastroenterology Unit, Maggiore Hospital, Pediatric Department, Bologna, Italy

Full list of author information is available at the end of the article
}

symptoms at presentation, or because it is completely silent [3]. Serum-prevalence data suggest that for each clinically diagnosed patient, an average of 5-10 seropositive individuals remains undiagnosed, usually due to atypical symptoms, minimal or even absent [3]. The understanding of epidemiological trends of $\mathrm{CD}$ in the early stages of life can guide the optimal approach to the rising burden of such an heterogeneous and widespread condition and its early diagnosis.

The pediatric clinical presentation of $\mathrm{CD}$ is extremely variable, characterized by intestinal and/or

\section{$\triangle B M C$}

(c) The Author(s). 2021 Open Access This article is licensed under a Creative Commons Attribution 4.0 International License, which permits use, sharing, adaptation, distribution and reproduction in any medium or format, as long as you give appropriate credit to the original author(s) and the source, provide a link to the Creative Commons licence, and indicate if changes were made. The images or other third party material in this article are included in the article's Creative Commons licence, unless indicated otherwise in a credit line to the material. If material is not included in the article's Creative Commons licence and your intended use is not permitted by statutory regulation or exceeds the permitted use, you will need to obtain permission directly from the copyright holder. To view a copy of this licence, visit http://creativecommons.org/licenses/by/4.0/ The Creative Commons Public Domain Dedication waiver (http://creativecommons.org/publicdomain/zero/1.0/) applies to the data made available in this article, unless otherwise stated in a credit line to the data. 
extraintestinal signs and symptoms variously combined. The most frequent gastrointestinal symptoms (GIs) include diarrhea, constipation, recurrent abdominal pain (RAP), bloating, and vomiting [4]. CD can also present with extra-intestinal symptoms (EIs) and signs hardly linkable to the disease, including anemia, delayed puberty, headache, recurrent dermatitis, dental enamel defects [5] and failure to thrive (FTT). Moreover, there are a number of asymptomatic patients with increased risk of $\mathrm{CD}$ due to first degree familiarity or presence of comorbidities [6], who are diagnosed through screening programs. The clinical presentation also changes according to age [4].

The aim of this study is to analyze how CD clinical presentation in children has changed in an Italian Pediatric referral Centre in the last 30 years, according to age and period at diagnosis, before or after 2012 guidelines for pediatric $\mathrm{CD}$ diagnosis [6].

\section{Methods}

We conducted an observational retrospective study in a population of children (age 18 years old) diagnosed with CD from January 1990 to March 2020 at the Pediatric Gastroenterology referral Centre for Celiac Disease of Maggiore Hospital in Bologna. Personal and clinical data were extracted from clinical reports of each patient and collected: sex, age at diagnosis, clinical presentation, familiar history of $\mathrm{CD}$, comorbidities, and patients identified by routinary screening.

All enrolled patients were diagnosed according to criteria from effective European $\mathrm{CD}$ guidelines at the time of medical examination. Up to 2011 small-bowel mucosal biopsies during esophagogastroduodenoscopy (EGDS) were required to confirm CD diagnosis [4]. According to 2012 guidelines from the European Society for Pediatric Gastroenterology, Hepatology and Nutrition (ESPGHAN), the histological assessment may be omitted in symptomatic patients who have IgA antitransglutaminase antibodies (TGA-IgA) 10 times above the upper limit of normal (ULN), verified by endomysial antibodies (EMA-IgA) positivity and HLADQ2 and/or HLA-DQ8 heterodimer [6]. Furthermore, the most recent update of the 2020 ESPGHAN guidelines provides the possibility of diagnosing $\mathrm{CD}$ in the absence of symptoms and predisposing HLA haplotype [1].

Our population was stratified into two groups based on the time at diagnosis: period 1 (P1) if patients were diagnosed between January 1990 and December 2011, period 2 (P2) between January 2012 and March 2020. These intervals were settled in order to have comparable groups and they consider the important changes in pediatric CD diagnosis after the 2012 ESPGHAN guidelines publication. Furthermore, we divided patients into 4 subgroups based on the age at diagnosis: group 1 (G1) age < 2 years old; group 2 (G2) age $2-5$ years; group 3 (G3) age 6-11 years; group 4 (G4) age 12-18 years old.

Patients were investigated by comparing clinical presentation of $\mathrm{CD}$ at diagnosis. We identified four categories of symptoms: GIs, which include diarrhea, RAP, constipation, vomiting/gastroesophageal reflux (GER), stomatitis and bloating; EIs, including anemia, dental enamel defects, neurological symptoms (headache, fainting/syncope, epilepsy), skin/appendages involvement (rashes, nail and hair alterations); FTT, defined as a significant height or weight deceleration compared with the reference rate for age and sex or compared with expected height based on parental height; screening group (first-degree familiarity for $\mathrm{CD}$, increased risk due to comorbidities such as autoimmune associated conditions, chromosomal abnormalities, or selective IgA deficiency, and patients with neither obvious symptoms nor risk factors). Each patient may have been assigned to more than one group.

The frequency of symptoms at presentation has been studied in relation either to the year of diagnosis and the age at the time of diagnosis. The study was approved by the local review board.

\section{Statistical analyses}

Continuous variables were expressed as means and standard deviations (SD), while categorical variables were presented as frequencies and percentages. Comparisons of continuous variables between more than two groups were carried out using the Kruskal-Wallis tests while the association between categorical variables was tested by means of the Fisher exact test or $\chi 2$, as appropriate. Tests were 2-sided and a $P<0.05$ was considered significant. Analyses were performed with STATA software 15.

\section{Results \\ Population}

We evaluated 1081 celiac children. 517 are included in $\mathrm{P} 1$ and 564 in P2. Concerning age groups, $13 \%(n=141)$ of patients are diagnosed within the first 2 years of life, $40,7 \%(n=440)$ from 2 to 5 years old, 37\% $(n=401)$ from 6 to 11 , and 9,2\% $(n=99)$ over 12 years old. Overall, the mean age at diagnosis is $6,3(\mathrm{SD} \pm 3,75)$ years old, median age is 5,6 [range $0,8-18$ ] years old. Female/male ratio is $1,9: 1$, with $66 \%,(n=718)$ of females. Overall, the most frequent clinical presentation is represented by GIs (44\%), followed by FTT (24\%) and EIs (15\%). Finally, 412 (38\%) children are detected by screening, of whom 226 (21\%) patients with no risk factors, 115 (11\%) with firstdegree familiarity for $\mathrm{CD}$, and $71(6 \%)$ present associated conditions. 


\section{Clinical trends in relation to periods}

Symptoms and demographic characteristics at presentation according to the 2 considered periods are reported in detail in Table 1.

The mean age at diagnosis gradually increases from 5.9 years old $(\mathrm{SD} \pm 3.82)$ in $\mathrm{P} 1$ to $6.6(\mathrm{SD} \pm 3.65)$ in $\mathrm{P} 2$ $(p<0.05)$.

Over the 30 examined years we observe a significant decrease in children diagnosed $<2$ years of age $(18 \%$ in $\mathrm{P} 1$ vs $8 \%$ in $\mathrm{P} 2, p<0,001)$, and an increase in patients detected at $6-11$ years old (32\% in P1 vs $42 \%$ in P2, $p<$ $0,001)$. Diagnosis at age $2-5$ and $12-18$ years old are statistically overlapping ( $p=0,85$ and $p=0,89$, respectively) in the two periods. We found an higher prevalence among females.

GIs are predominant for frequency in P1 (35\%) and P2 (52\%). In detail, in both considered periods RAP is prevailing ( $48 \%$ in $\mathrm{P} 1,51 \%$ in $\mathrm{P} 2$ ), followed by diarrhea (47\% in P1, 30\% in P2), vomiting/GER (13\% in P1, $10 \%$ in P2) and constipation (4\% in P1, 19\% in P2). Comparing the prevalence of each GIs in the 2 studied periods we find that diarrhea significantly decreases over the years $(p<0.001)$, while constipation and bloating increase $(p<0.001)$.

EIs are less frequent in both P1 (14\%) and P2 (15\%), without differences in the two periods $(p=0.54)$. Neurological associated symptoms are represented by headache in all patients of our sample. In P1 the most frequent EIs is anemia, which significantly decreases from P1 to P2 ( $76 \%$ vs $43 \% ; p<0.001)$, while neurological manifestations and skin involvement increase $(p<0,05)$.

Recurrence of FTT is stable throughout the years $(27 \%$ in $\mathrm{P} 1$ vs $21 \%$ in $\mathrm{P} 2, p=0.03$ ).

The overall percentage of patients identified by screening also remains stable over the 30 years. However, if we exclude from this group children who were screened because of a family history for CD (29\% in P1 and $27 \%$ in P2) or comorbidities (22\% in $\mathrm{P} 1$ and $13 \%$ in P2), we find that patients without any risk factor grow from $18,7 \%$ in $\mathrm{P} 1$ to $22,9 \%$ in P2, on the total sample. The difference doesn't reach a statistical significance, but

TABLE 1 Clinical presentation of celiac disease in relation to the two considered periods

\begin{tabular}{|c|c|c|c|c|}
\hline & $\begin{array}{l}\text { P1 } \\
(1990-2011) \\
n=517 \\
n(\%)\end{array}$ & $\begin{array}{l}\mathrm{P} 2 \\
(2012-2020) \\
n=564 \\
n(\%)\end{array}$ & $p$ value & $\begin{array}{l}\text { Total } \\
1081 \\
\mathrm{n}(\%)\end{array}$ \\
\hline \multicolumn{5}{|l|}{ Symptoms } \\
\hline GASTROINTESTINAL & $182(35 \%)$ & $294(52 \%)$ & $p<0.001$ & 476 (44\%) \\
\hline Diarrhea & 85 (47\%) & $88(30 \%)$ & $p<0.001$ & $173(36 \%)$ \\
\hline Recurrent abdominal pain & 87 (48\%) & $150(51 \%)$ & $p=0.49$ & 237 (50\%) \\
\hline Constipation & $8(4 \%)$ & 57 (19\%) & $p<0.001$ & $65(14 \%)$ \\
\hline Vomit / GER & $23(13 \%)$ & $28(10 \%)$ & $p=0.29$ & $51(11 \%)$ \\
\hline Stomatitis / Aftosis & $1(1 \%)$ & $10(3 \%)$ & $P=0.06$ & $11(2 \%)$ \\
\hline Bloating & $2(1 \%)$ & $36(12 \%)$ & $p<0.001$ & $38(8 \%)$ \\
\hline EXTRAINTESTINAL & $72(14 \%)$ & $86(15 \%)$ & $p=0.54$ & $158(15 \%)$ \\
\hline Anemia & $55(76 \%)$ & $37(43 \%)$ & $p<0.001$ & $92(58 \%)$ \\
\hline Neurologic symptoms & $7(10 \%)$ & $21(24 \%)$ & $p=0.02$ & $28(18 \%)$ \\
\hline Skin & $9(13 \%)$ & $25(29 \%)$ & $p=0.01$ & $34(22 \%)$ \\
\hline Dental Enamel Defects & $1(1 \%)$ & $6(7 \%)$ & $p=0.13$ & $7(4 \%)$ \\
\hline SCREENING & 199(38\%) & 213(38\%) & $p=0.81$ & $412(38 \%)$ \\
\hline Absence of symptoms/risk factors & $97(49 \%)[19 \%]^{*}$ & $129(60 \%)[23 \%]^{*}$ & $p=0.09$ & $226(55 \%)[21 \%]^{*}$ \\
\hline 1st degree familiarity & $58(29 \%)$ & $57(27 \%)$ & $p=0.61$ & $115(28 \%)$ \\
\hline Autoimmune associated conditions & $44(22 \%)$ & $27(13 \%)$ & $p=0.01$ & $71(17 \%)$ \\
\hline FAILURE TO THRIVE & $140(27 \%)$ & $121(21 \%)$ & $P=0.03$ & $261(24 \%)$ \\
\hline \multicolumn{5}{|l|}{ Age Groups } \\
\hline G1 (<2.0 years) & 94 (18\%) & $47(8 \%)$ & $p<0.001$ & $141(13 \%)$ \\
\hline G2 (2.1-6.0 years) & $212(41 \%)$ & $228(40 \%)$ & $p=0.85$ & 440 (41\%) \\
\hline G3 (6.1-12.0 years) & $163(32 \%)$ & $238(42 \%)$ & $p<0.001$ & 401 (37\%) \\
\hline G4 (12.1-18 years) & $48(9 \%)$ & $51(9 \%)$ & $p=0.89$ & $99(9 \%)$ \\
\hline
\end{tabular}

[]* \% on the total period's sample 
we observe a trend of increase in diagnosis from routinary screening programs.

\section{Clinical trends in relation to age at diagnosis}

Symptoms and demographic characteristics at presentation according to the 4 considered age groups are reported in Fig. 1.

GIs' frequency significantly decreases with the raise of age at diagnosis: $\mathrm{G} 1$ has the highest rate (67\%), followed by G2 (46\%), G3 (37\%), and G4 (33\%). In detail, there is a gradual decrease of diarrhea from G1 to G4 (66\% vs $24 \%, p<0.001)$, while RAP has an opposite trend (20\% in G1 vs $75 \%$ in G4, $p=0,02$ ). The frequency of constipation does not change in relation to the different age groups $(p=0.38)$. Finally, we observe a decrease in the incidence of vomiting $(p<0,001)$ and bloating $(p=0,01)$ from G1 to G4.

With regard to EIs, we observe a significantly lower frequency in G1 compared to other age groups ( $p=$ $0,02)$. Concerning anemia, G2 has the higher frequency among all age groups $(p=0,01)$. Neurological symptoms are lower in $\mathrm{G} 2$ than in all older age groups $(p<0.05)$.

The frequency of FTT gradually decreases with the raise of age at diagnosis $(p<0.05)$.
The frequency of screenings gradually increases from $17 \%$ in $\mathrm{G} 1$ to $51 \%$ in $\mathrm{G} 4(p<0.05)$. With regard to patients with no obvious symptoms nor risk factors, their frequency is significantly higher in G4 (70\%) than G1 $(46 \%)$ and G2 $(49 \%),(p<0.05)$. On the contrary, in younger patients the frequency of $\mathrm{CD}$ diagnosis by family screening is higher than in the older age groups (G1 and G2 33\% vs G4 14\%; $p<0.05$ ). There are no relevant differences between the age groups in relation to comorbidities.

\section{Discussion}

Data presented in this research highlight significant changes in clinical presentation of pediatric $\mathrm{CD}$ in the last 30 years, in the wider population so far reported in the literature. Several smaller studies documented changes in the clinical pattern of pediatric CD [7-11] in the last decades. In particular, different authors have demonstrated a progressive increase of age at diagnosis throughout the years $[7,8,11,12]$. We confirm a comparable trend, however, we report a lower mean age at diagnosis than both Northern and Southern Europe [8, 11, 13] and United States of America (USA) [7, 14]. In the last decade, the average age at diagnosis in our

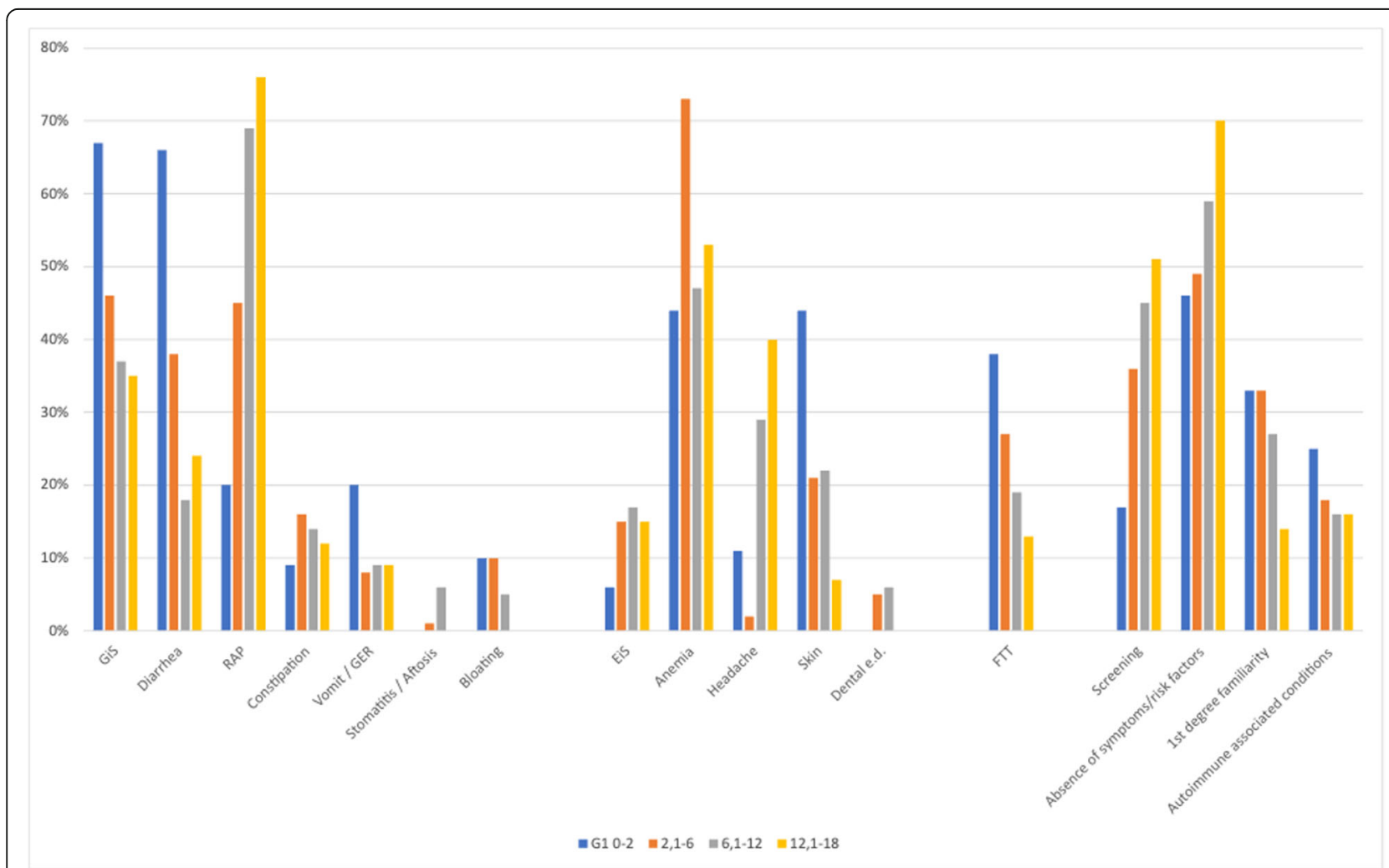

(GiS) Gastrointestinal symptoms; (RAP) Recurrent abdominal pain; (GER) Gastroesophageal reflux; (EiS) Extraintestinal symptoms; (FTT) Failure to Thrive.

Fig. 1 Symptoms related to age groups 
population is 6.6 years compared to over 9 years in other areas $[8,14]$. These findings agree with previous studies conducted in the Mediterranean area, that found average ages of 5.5-6 years old [10, 12]. Different infant feeding practises could influence the age at diagnosis and clinical CD presentation. A possible explanation is that in Italy there is a higher intake of gluten in the first years of life. Indeed, according to the Food and Agricultural Organization (FAO), in Italy daily wheat supply quantity corresponds to $401.2 \mathrm{~g} / \mathrm{capita} /$ day, whereas in Northern Europe and USA it is respectively 263.5 and $220.36 \mathrm{~g} /$ capita/day [15]. Moreover, in our geographical area gluten is introduced earlier in childrens' diet. According to Lionetti E. et al. [16], a delayed gluten introduction, although it does not affect the onset of $\mathrm{CD}$, is associated with a delayed onset of the disease. In second place, breastfeeding's duration could influence the age of CD onset. In 2016 ESPGHAN stated that breastfeeding does not reduce the risk of $C D$ in children [17], but several evidences speculate that prolonged breastfeeding delays the onset of symptoms $[18,19]$. In Italy breastfed infants at 6 months of life are 38\% while in Sweden and Norway they are respectively 61 and $71 \%$ [20]. The increased age at diagnosis of the last decade in our population is related to a significant decrease of patients $<6$ years old, and a progressive rise in children with age 6-12 years. This may be explained by the expanding implementation of routinary screening programs in asymptomatic patients and the increasing awareness about atypical signs and symptoms of $\mathrm{CD}$ or Eis, mainly in older patients [21].

In our study GIs are the dominant symptoms that lead to $\mathrm{CD}$ diagnosis at all times (35-52\%) increasing in our case series over the past 30 years, but fewer than in other countries [8], as reported in a Swedish study conducted between 1973 and 2013 (71-82\%) [8].

GIs' prevalence, mainly in younger children, may occur because they are the most striking symptoms and likely to be detected by parents and clinicians.

RAP remains the predominant GI symptom over the time and its frequency increases in older children, presumably because the pain has to be reported directly by the patient. In the European Union (EU) pediatric population, RAP has been recently identified as the most represented symptom in all Countries except for Italy [14], however, our results from a much larger sample, although monocentric, seem to align the Italian trend with the rest of EU countries. In accordance with our findings, a large British study of 13,971 children observe that RAP is reported in $11.8 \%$ of 6 -years-old children [22], while it is less common at the age of $2(3.8 \%)$ and 3 (6.9\%). We should also notice that sometimes RAP is functional and does not relate to $\mathrm{CD}$, as already suggested in the literature [23]. Unlike RAP, diarrhea and vomiting are declining throughout the ages in our sample, probably due to the improvement in diagnostic skills about these early, traditional and severe symptoms. On the other hand, we notice a rise of less common GIs like constipation and bloating. In accordance with these findings, in recent years constipation has been recognized as a symptom related to $\mathrm{CD}$ that needs to be investigated [24].

In the literature there are no univocal data about the course of EIs over time. In particular, a recent study [9] reports a steady trend of anemia, while other sources [8, 11] report a reduction in EIs over time. Overall, their prevalence is stable throughout the considered time in our population. Among EIs, anemia is prevailing in all periods but it's frequency is declining in P2, probably due to a reduction of severe gastrointestinal forms of malabsorption in recent years. We may remember that even though anemia is commonly associated with severe mucosal atrophy, it can be the only sign of CD [25]. Furthermore, we observe an increase in neurological manifestations and skin/appendages involvement through the years. A better detection of non-classic presentations may be related to an improved primary-care pediatricians' awareness, thanks to continuous educational programs. In Emilia Romagna, which has almost 18,000 celiac patients both adults and children [26] (4.459.000 inhabitants), a regular training is carried out by pediatric gastroenterologists to general pediatricians, in order to allow adequate prescriptions of blood test examinations for $\mathrm{CD}$ and an early referral to the specialist of suspected children. Moreover, since the only neurological manifestation in our sample is headache, we specify that in our hospital coexists a pediatric neuropsychiatry tertiary-level centre where many children are referred for this condition. EIs' lower frequency in patients $<2$ years old compared to other age groups, suggests a later onset of these symptoms. Anemia is more frequent at 26 years of age, and this may be a consequence of a delay in detecting severe forms of malabsorption in which anemia is the only sign.

We found no significant differences about FTT recurrence among the examined periods, while both in Northern Europe and USA a few studies report decreasing trends in the last years $[7,8,11]$.

We observe a tendency of increase in patients identified from routinary screening programs in the last decade. This can be explained by the growing diffusion of screening practices for patients with a firstdegree relative affected by $\mathrm{CD}$, or even asymptomatic children without any risk factor. However, in our series, the patients identified through screening programs are predominantly older than 2 , as blood tests are rarely performed before this age in the absence of symptoms. 
There are some weaknesses in this research. It is a retrospective and monocentric study, even if our Centre is a referral one and our cohort is the largest among the published literature on the issue. Therefore, despite these limitations, we believe that our results are a helpful contribution to the understanding of current CD clinical presentation and give fundamental support to the existing literature.

In conclusion, we can assess that significant changes in clinical presentation of pediatric $\mathrm{CD}$ have occurred in the last 30 years. The average age at diagnosis has increased throughout the decades and it confirms to be lower compared to other Countries; this may be related to specific Italian environmental factors such as diet and breastfeeding practises. GIs represent the main symptoms at onset, mostly in younger patients, but we recently recorded a progressive reduction of severe and classic signs and symptoms and a rise of atypical clinical patterns. Furthermore, in the last decades, more asymptomatic children are diagnosed by serological screening programs. It is crucial to monitor the clinical trends of $\mathrm{CD}$ in order to improve awareness, for a proper approach and an early diagnosis.

\section{Abbreviations}

CD: Celiac Disease; GFD: Gluten-Free-Diet; Gls: gastrointestinal symptoms; RAP: recurrent abdominal pain; Els: extra-intestinal symptoms; FTT: failure to thrive; GER: gastroesophageal reflux

\section{Acknowledgements}

Not Applicable.

\section{Authors' contributions}

MP Substantial contributions to the conception and design of the work, the acquisition, analysis, and interpretation of data for the work; AND drafting the work and revising it critically for important intellectual content; AND final approval of the version to be published; AND agreement for all aspects of the work in ensuring that questions related to the accuracy or integrity of any part of the work are appropriately investigated and resolved. FS Substantial contributions to the conception and design of the work, the acquisition, analysis, and interpretation of data for the work; AND drafting the work and revising it critically for important intellectual content; AND final approval of the version to be published; AND agreement for all aspects of the work in ensuring that questions related to the accuracy or integrity of any part of the work are appropriately investigated and resolved. DA Substantial contributions to the elaboration of data for the work; AND revising the work critically for important intellectual content; AND final approval of the version to be published; AND agreement for all aspects of the work in ensuring that questions related to the accuracy or integrity of any part of the work are appropriately investigated and resolved. FL Substantial contributions to the design of the work, and the acquisition of data for the work; AND revising the work critically for important intellectual content; AND final approval of the version to be published; AND agreement for all aspects of the work in ensuring that questions related to the accuracy or integrity of any part of the work are appropriately investigated and resolved. VL Contribution to the acquisition of data for the work; AND final approval of the version to be published; AND agreement for all aspects of the work in ensuring that questions related to the accuracy or integrity of any part of the work are appropriately investigated and resolved. ES Final approval of the version to be published; AND agreement for all aspects of the work in ensuring that questions related to the accuracy or integrity of any part of the work are appropriately investigated and resolved. CZ Contribution to the acquisition of data for the work; AND final approval of the version to be published; AND agreement for all aspects of the work in ensuring that questions related to the accuracy or integrity of any part of the work are appropriately investigated and resolved. PA Substantial contributions to the conception and design of the work, the acquisition, analysis, and interpretation of data for the work; AND drafting the work and revising it critically for important intellectual content; AND final approval of the version to be published; AND agreement for all aspects of the work in ensuring that questions related to the accuracy or integrity of any part of the work are appropriately investigated and resolved. All authors read and approved the final manuscript.

\section{Funding}

No fund supported our study.

\section{Availability of data and materials}

All data generated or analysed during this study are included in this published article.

\section{Declarations}

Ethics approval and consent to participate

Approved by the local ethics committee (CE 20127 rif CE AVEC 750_2020_OSS_AUSLBO).

\section{Consent for publication}

Not applicable.

\section{Competing interests}

The authors declare that they have no competing interests.

\section{Author details}

'Specialty School of Paediatrics - Alma Mater Studiorum, University of Bologna, Bologna, Italy. ${ }^{2}$ Pediatric Gastroenterology Unit, Maggiore Hospital, Pediatric Department, Bologna, Italy. ${ }^{3}$ Department of Clinical Governance and Quality, Bologna Local Healthcare Authority, Bologna, Italy. ${ }^{4}$ Department of Biological, Geological and Environmental Sciences, University of Bologna, Bologna, Italy.

Received: 30 May 2021 Accepted: 10 November 2021

Published online: 14 December 2021

References

1. Husby S, Koletzko S, Korponay-Szabó I, Kurppa K, Mearin ML, Ribes-Koninckx C, et al. European society Paediatric gastroenterology, hepatology and nutrition guidelines for diagnosing coeliac disease 2020. J Pediatr Gastroenterol Nutr. 2020;70(1):141-56. https://doi.org/10.1097/MPG. 0000000000002497.

2. Hoffenberg EJ, MacKenzie T, Barriga KJ, Eisenbarth GS, Bao F, Haas JE, et al. A prospective study of the incidence of childhood celiac disease. J Pediatr. 2003;143(3):308-14. https://doi.org/10.1067/S0022-3476(03)00282-8.

3. Lindfors K, Ciacci C, Kurppa K, Lundin KEA, Makharia GK, Mearin ML, et al. Coeliac disease. Nat Rev Dis Prim. 2019;5(1):3. https://doi.org/10.1038/s41 572-018-0054-z.

4. Hill ID, Dirks MH, Liptak GS, Colletti RB, Fasano A, Guandalini S, et al. Guideline for the diagnosis and treatment of celiac disease in children: recommendations of the north American Society for Pediatric Gastroenterology, hepatology and nutrition. J Pediatr Gastroenterol Nutr. 2005:40(1):1-19. https://doi.org/10.1097/00005176-200501000-00001.

5. Nardecchia S, Auricchio R, Discepolo V, Troncone R. Extra-intestinal manifestations of coeliac disease in children: clinical features and mechanisms. Front Pediatr. 2019;7:56. https://doi.org/10.3389/fped.2019. 00056.

6. Husby S, Koletzko S, Korponay-Szabó IR, Mearin ML, Phillips A, Shamir R, et al. European Society for Pediatric Gastroenterology, hepatology, and nutrition guidelines for the diagnosis of coeliac disease. J Pediatr Gastroenterol Nutr. 2012;54(1):136-60. https://doi.org/10.1097/MPG.0b013 e31821a23d0.

7. McGowan KE, Castiglione DA, Butzner JD. The changing face of childhood celiac disease in North America: impact of serological testing. Pediatrics. 2009;124(6):1572-8. https://doi.org/10.1542/peds.2008-2373.

8. Tapsas D, Hollén E, Stenhammar L, Fälth-Magnusson K. The clinical presentation of coeliac disease in 1030 Swedish children: changing features 
over the past four decades. Dig Liver Dis. 2016;48(1):16-22. https://doi.org/1 0.1016/j.dld.2015.09.018.

9. Krauthammer A, Guz-Mark A, Zevit N, Marderfeld L, Waisbourd-Zinman O, Silbermintz A, et al. Two decades of pediatric celiac disease in a tertiary referral center: what has changed. Dig Liver Dis [Internet]. 2020;52(4):45761. https://doi.org/10.1016/j.dld.2020.02.001.

10. Tucci F, Astarita L, Abkari A, et al. Celiac disease in the Mediterranean area. BMC Gastroenterol. 2014;14(1):1-7.

11. Kivelä L, Kaukinen K, Lähdeaho ML, et al. Presentation of Celiac Disease in Finnish Children Is No Longer Changing: A 50-Year Perspective Portions of this study were presented orally at the 47th Annual Meeting of the European Society for Pediatric Gastroenterology, Hepatology and Nutrition ESPGHAN. J Pediatr. 2015;167(5):1109-15.e1.

12. Garampazzi A, Rapa A, Mura S, Capelli A, Valori A, Boldorini R, et al. Clinical pattern of celiac disease is still changing. J Pediatr Gastroenterol Nutr. 2007; 45(5):611-4. https://doi.org/10.1097/MPG.0b013e31814c3d79.

13. Riznik P, De Leo L, Dolinsek J, et al. Clinical presentation in children with coeliac disease in Central Europe. J Pediatr Gastroenterol Nutr. 2021;72(4): 546-51. https://doi.org/10.1097/MPG.0000000000003015 PMID: 33306584.

14. Tanpowpong P, Broder-Fingert S, Katz AJ, Camargo CA. Age-related patterns in clinical presentations and gluten-related issues among children and adolescents with celiac disease. Clin Transl Gastroenterol [Internet]. 2012; 3(2):e9. https://doi.org/10.1038/ctg.2012.4.

15. FAOSTAT. Available from: http://www.fao.org/faostat/en/\#compare

16. Lionetti $\mathrm{E}$, Castellaneta S, Francavilla R, Pulvirenti A, Tonutti E, Amarri S, et al. Introduction of gluten, HLA status, and the risk of celiac disease in children. N Engl J Med. 2014;371(14):1295-303. https://doi.org/10.1056/NEJMoa1400697.

17. Szajewska H, Shamir R, Mearin L, Ribes-Koninckx C, Catassi C, Domellöf M, et al. Gluten introduction and the risk of coeliac disease: a position paper by the european society for pediatric gastroenterology, hepatology, and nutrition. J Pediatr Gastroenterol Nutr. 2016;62(3):507-13. https://doi.org/10.1 097/MPG.00000000000001105.

18. Auricchio $S$, Follo $D$, de Ritis $G$, et al. Does breast feeding protect against the development of clinical symptoms of celiac disease in children. J Pediatr Gastroenterol Nutr. 1983;2(3):428-33. https://doi.org/10.1097/000051 76-198302030-00006

19. Greco L, Mayer M, Grimaldi M, Follo D, Ritis GD, Auricchio S. The effect of early feeding on the onset of symptoms in celiac disease. J Pediatr Gastroenterol Nutr. 1985;4(1):52-5. https://doi.org/10.1097/00005176-198502 000-00010.

20. Theurich MA, Davanzo R, Busck-Rasmussen M, Díaz-Gómez NM, Brennan C, Kylberg E, et al. Breastfeeding rates and programs in europe: a survey of 11 national breastfeeding committees and representatives. J Pediatr Gastroenterol Nutr. 2019;68(3):400-7. https://doi.org/10.1097/MPG 0000000000002234.

21. Namatovu F, Sandström O, Olsson C, Lindkvist M, Ivarsson A. Celiac disease risk varies between birth cohorts, generating hypotheses about causality: evidence from 36 years of population-based follow-up. BMC Gastroenterol. 2014;14:59. https://doi.org/10.1186/1471-230X-14-59 PMID: 24693975; PMCI D: PMC3977663.

22. Ramchandani PG, Hotopf M, Sandhu B, Stein A, ALSPAC Study Team. The epidemiology of recurrent abdominal pain from 2 to 6 years of age: results of a large, population-based study. Pediatrics. 2005;116(1):46-50. https://doi. org/10.1542/peds.2004-1854.

23. Saps M, Adams P, Bonilla S, Nichols-Vinueza D. Abdominal pain and functional gastrointestinal disorders in children with celiac disease. J Pediatr. 2013;162(3):505-9. https://doi.org/10.1016/j.jpeds.2012.08.032.

24. Baker SS, Liptak GS. Colletti RBet al. Constipation in infants and children: evaluation and treatment. A medical position statement of the north American society for pediatric gastroenterology and nutrition. J Pediatr Gastroenterol Nutr. 1999;29(5):612-26. https://doi.org/10.1097/00005176-1 99911000-00029.

25. Repo M, Lindfors K, Mäki M, Huhtala H, Laurila K, Lähdeaho ML, et al. Anemia and Iron deficiency in children with potential celiac disease. J Pediatr Gastroenterol Nutr. 2017;64(1):56-62. https://doi.org/10.1097/MPG. 0000000000001234.

26. Emilia-Romagna R. Celiachia, in Emilia-Romagna arrivano le linee guida per la diagnosi precoce e il monitoraggio della malattia. In: . Available from: https://salute.regione.emilia-romagna.it/notizie/il-fatto/celiachia-in-emiliaromagna-arrivano-le-linee-guida-per-la-diagnosi-precoce-e-il-monitoraggiodella-malattia.

\section{Publisher's Note}

Springer Nature remains neutral with regard to jurisdictional claims in published maps and institutional affiliations.
Ready to submit your research? Choose BMC and benefit from:

- fast, convenient online submission

- thorough peer review by experienced researchers in your field

- rapid publication on acceptance

- support for research data, including large and complex data types

- gold Open Access which fosters wider collaboration and increased citations

- maximum visibility for your research: over $100 \mathrm{M}$ website views per year

At $\mathrm{BMC}$, research is always in progress.

Learn more biomedcentral.com/submissions 